\title{
Inactivation of Microcystis Aeruginosa by High Voltage Electrical Discharges
}

\author{
Wanlin Zhang a , Ying Gao ${ }^{b}$, Wei Wu ${ }^{\text {c, }}$, Weiwei Wang ${ }^{\mathrm{d}}$, and $\mathrm{Li} \mathrm{Li}^{\mathrm{e}}$ \\ School of Southeast University, Jiangsu 210009, China. \\ a1292665976@qq.com, b3236027533@qq.com, c101005800@seu.edu.cn, d1715556404@qq.com, \\ e1404157708@qq.com
}

Keywords: Microcystis aeruginosa, high voltage electrical discharge, algae removal.

\begin{abstract}
Harmful cyanobacterial blooms have occurred worldwide over the past several decades, these blooms cause a series of problems not only on drinking water supplies, food webs, but also on the sustainability of freshwater ecosystems. In this study, we constructed a liquid-phase high voltage discharge system to evaluate the effect of high voltage discharge on the growth of Microcystis aeruginosa. Experimental results showed that when the algae initial concentration was $1 \times 10^{6} \mathrm{cells} / \mathrm{ml}$, there was almost no change in optical density immediately after the electrical discharge, which presents the cell concentration of Microcystis aeruginosa was not changed immediately. While during the cell cultivating time after the discharge for five days, the cell concentration was gradually decreased along with the cultivating days compared with the control group. And among the treated groups, the $5 \mathrm{kV}$ group and the $4 \mathrm{kV}$ groups' effect was superior than the $3 \mathrm{kV}$ groups $(P<0.05)$, but there was no differences between the $5 \mathrm{kV}$ groups and the $4 \mathrm{kV}$ groups $(P>0.05)$. While the microcystin-LR(MC-LR) content was different between the $5 \mathrm{kV}$ groups and the $4 \mathrm{kV}$ groups $(P<0.05)$ after discharge for 5 days detected by high performance liquid phase (HPLC). These results implicated that the growth inhibition of $M$. aeruginosa was mainly caused by electrical discharge process, and it made the algal cells lose ability to survive, demonstrating the considerable potential of such an alternative process for efficient water purification.
\end{abstract}

\section{Introduction}

Cyanobacteria, or blue bacteria, is the world's oldest planktonic prokaryotes, but also the main algae species formatting the harmful cyanobacterial in fresh water, rivers and harbor ecological environment [1]. The growth of cyanobacteria is related to hydrology, light intensity, ambient temperature, available nutrients and other ecosystem disturbances. Cyanobacteria blooms can be caused by a variety of environmental factors: water nutrient content, temperature, light, fluid mechanics and cyanobacteria's own conditions such as buoyancy regulation level, nitrogen fixation capacity, and nutritional storage function [2].

Nowadays, cyanobacteria has been outbroken in more than 60 countries around the world and has caused human or animal disease and death in more than 50 countries [3]. The annual economic losses caused by cyanobacteria bloom due to eutrophication are about $\$ 2.2$ billion [4-6]. Blue algae blooms suggest that water bodies, animal habitats, drinking water, food chains and sustainable freshwater systems are facing significant threats [7-10]. In addition, microcystins and cyano toxins released by cyanobacteria are increasingly considered to be one of the major problems affecting water quality worldwide, which can caused neurotoxicity, hepatotoxicity and gastrointestinal disorders by direct contact with, inhalation or ingestion of contaminated water during human activities [11,12].

Advanced oxidation processes (AOPs) are innovative tools that involve an introduction of energy (e.g., chemical, electrical and radiative) into the reaction zone to generate highly reactive species, especially hydroxyl radicals whose standard potentials are up to $2.8 \mathrm{~V}$ in acidic media [13]. Over the past few decades, experimental investigations have revealed that algae can be inactivated by advanced oxidation processes, including ozone, hydrogen peroxide, UV photolysis, c-irradiation and various combinations of these methods, all these results indicate AOPs are important for algal control in 
drinking water purification. For water algae purification in the application of electrical discharge plasma technology, non-thermal plasma, one of AOPs usually generated by high voltage electrical discharges (HVED).

The application of HVED is based on the phenomenon of electrical breakdown in water. Air bubbles that are initially present in water or formed due to local heating are involved into this phenomenon and accelerate the process. If the electrical field is intense enough, the avalanche of electrons becomes a starting point of streamer propagation from the high voltage needle electrode to the grounded one. A track from the discharge channel can be attracted by a solid inclusion if dielectric properties of the medium and inclusion are different. The electrical breakdown is accompanied by the number of secondary phenomena (high-amplitude pressure shock waves, bubbles cavitation, creation of liquid turbulence, etc.). These secondary phenomena cause particle fragmentation and cell structure damage. They can also accelerate extraction of biomolecules from the cytoplasm of the cells [14].The electrical discharge plasma technology leads to various physical and chemical effects, such as primary formation of oxidizing species: radicals $(\mathrm{H} \cdot, \mathrm{O} \cdot, \mathrm{OH} \cdot)$ and molecules $\left(\mathrm{H}_{2} \mathrm{O}_{2}, \mathrm{O}_{3}\right.$, etc.), shockwave, ultraviolet light and electrohydraulic cavitation [15].

The mechanism for direct discharge in liquid is very intricate since water as a discharge medium is much denser than gases and does not express the long periodic range of the atomic and molecular as in most solids. In electrical liquid discharge, the current is transferred by slow ions in water that is strongly affected by liquid conductivity. Moreover, the purity, such as dissolved gases which form micro-bubbles in the liquid, plays a significant role in the breakdown process. So some physical principles are difficult to determine. For instance, regarding liquid electrical breakdown in liquids under pulsed excitation, the detailed mechanism is still not fully understood and there are primary two principal competing schools, namely, an electron multiplication theory and a phase change mechanism breakdown theory [13].

(1) $\mathrm{OH} \cdot$ and $\mathrm{H} \cdot$

The addition of water molecules into electrical discharge process leads to generating $\mathrm{OH}$ - and $\mathrm{H}$. via dissociation, ionization and vibrational/rotational excitation of water molecules, main reactions are as follow:

Dissociation: $\mathrm{H}_{2} \mathrm{O} \cdot+\mathrm{e} \rightarrow \mathrm{OH} \cdot+\mathrm{H} \cdot+\mathrm{e}$

Ionization: $\mathrm{H}_{2} \mathrm{O}+\mathrm{e} \rightarrow 2 \mathrm{e}+\mathrm{H}_{2} \mathrm{O}^{+}$

$\mathrm{H}_{2} \mathrm{O}^{+}+\mathrm{H}_{2} \mathrm{O} \rightarrow \mathrm{OH}^{-}+\mathrm{H}_{3} \mathrm{O}+$

(2) $\mathrm{O} \cdot$ and $\mathrm{O}_{2}^{-}$

When oxygen is exposure to electrical discharge, $\mathrm{O}$ atom $\left(\mathrm{E}^{0} \mathrm{O} / \mathrm{H} 2 \mathrm{O}=2.42 \mathrm{~V}\right)$ can be generated via dissociation of $\mathrm{O}_{2}$ and boosts the rate of production of $\mathrm{OH} \cdot$ as Eq.

$\mathrm{O} \cdot+\mathrm{H}_{2} \mathrm{O} \rightarrow 2 \mathrm{OH}^{\cdot}$

(3) $\mathrm{O}_{3}$ and $\mathrm{HO}_{2}^{-}$

Furthermore, $\mathrm{O}$ atom can directly react with contaminants and also takes part in the reactions with $\mathrm{O}_{2}$ resulting in the formation of $\mathrm{O}_{3}$. Ozone is unstable and decomposes through a cyclic chain mechanism to produce hydroxyl radicals in neutral and basic solutions. Moreover, with the presence of $\mathrm{H}_{2} \mathrm{O}_{2}$ in plasma system, ozone can react with $\mathrm{HO}_{2}^{-}$giving $\mathrm{OH} \cdot \mathrm{Eq}$.

$$
\begin{aligned}
& \mathrm{H}_{2} \mathrm{O}_{2} \rightarrow \mathrm{H}^{+}+\mathrm{HO}_{2}^{-} \\
& \mathrm{O}_{3}+\mathrm{HO}_{2}^{-} \rightarrow \cdot \mathrm{O}_{2}^{-} 2+\mathrm{OH} \cdot+\mathrm{O}_{2}
\end{aligned}
$$

(4) UV light

All plasmas containing water have UV light emission as a result of exited species relaxation to lower energetic states, which are generated from the collisions between electrons and neutral molecules. In organic degradation processes, when an organic molecule (M) is irradiated by UV light, it absorbs the radiation and gets promoted to an excited state $\left(\mathrm{M}^{*}\right)$. Then, the excited molecule $\mathrm{M}^{+}$ immediately returns to the ground state due to its short lifetime $\left(10^{-9}-10^{-8} \mathrm{~s}\right)$ through which excited molecule can decompose into new molecules. 
$\mathrm{M}+\mathrm{hv} \rightarrow \mathrm{M}^{*} \rightarrow$ products

(4) Shock wave

In electrical discharge processes, the expansion of the plasma channel against the surrounding water generates an intense shockwave. Thus, shockwave can be produced by high electric energy only introduced directly in the liquid or in bubbles. The resulting shockwave can induce pyrolytic and chemical reactions in bulk liquid indirectly via electrohydraulic cavitation. For example, more $\mathrm{OH} \cdot$ and $\mathrm{H}_{2} \mathrm{O}_{2}$ in the bulk liquid can be produced via dissociation of water induced by shockwaves.

\section{Materials and methods}

\subsection{Experimental setup and apparatus.}

Figure. 1 shows the schematic diagram of the HVED experimental system. The system mainly consists of (1) a $0-70 \mathrm{kV}$ adjustable high voltage DC power supply, (2) a $5 \mathrm{kV}$ high voltage transformer, (3) four rectifier diodes, (4) two current limiting resistors, (5)a $0.5 \mu \mathrm{F} / 30 \mathrm{kV} / 2 \mathrm{~A}$ non - inductive capacitors, (6) a $0-100 \mathrm{kV}$ voltmeter, (7) a pair of needle electrodes, (8) algae water treatment tube, the algae water treatment tube was a $15 \mathrm{~cm}$ high, $6 \mathrm{ccm}$ diameter plastic cylinder.

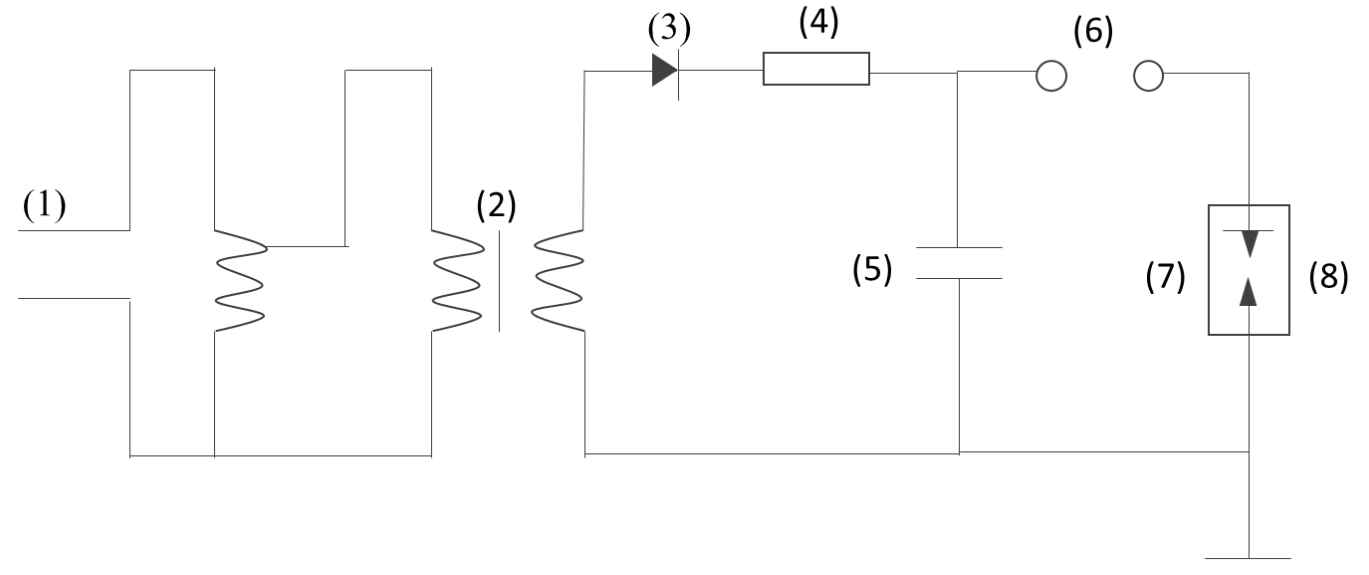

Figure. 1 The schematic diagram of the high voltage electrical discharge system

\subsection{Algae and its culture environment.}

Microcystis aeruginosa is FACHB-905, which were purchased from Wuhan Institute of Hydrobiology, Chinese Academy of Sciences in Wuhan, China. M. aeruginosa cells was cultivated at $25^{\circ} \mathrm{C}$ in axenic BG-11 medium. Illumination intensity was 2000 Lux with a light-dark cycle of $12 \mathrm{~h}$ : $12 \mathrm{~h}$. The $\mathrm{pH}$ of the algal suspension was around 8. Algae were grown to exponential phase and then used for high voltage electrical discharge treatment experiments. As $680 \mathrm{~nm}$ is the maximal absorbance band of $M$. aeruginosa cell suspensions, the cell concentration was measured by $722 \mathrm{~N}$ spectrophotometer at this wavelength. The concentration of algae used in this study was about $1 \times 10^{6}$ cells $/ \mathrm{ml}$, corresponding to $\mathrm{OD}_{680}=0.074$, which was also the initial algae concentration.

\subsection{Experimental procedure}

To investigate the direct effect of high voltage electrical discharge on the growth of M. Aeruginosa, a total of $250 \mathrm{ml}$ of algal water was poured into the treatment tube and treated for different treatment voltage for same times. At appropriate intervals, the samples were taken out from the reactor for analysis to determine the changes in OD value of the reaction medium immediately after the interruption of electrical discharge. It is also important to know how electrical discharge process affects the potential of cells to grow in the reaction medium after electrical discharge process was stopped. Therefore, treated samples were subjected to optical light and temperature condition plant, which were $24 \pm 1{ }^{\circ} \mathrm{C}$ temperature under illumination on a $12 \mathrm{~h} / 12 \mathrm{~h}$-light/dark cycle with 2000lux light intensity for 1-5 days incubation, to determine the changes in OD during the incubation period. The control group, which has not been treated by electrical discharge, was also exposed to the same conditions as the test samples. All the experiments were performed in triplicate and the average results 
are presented in the figures. The MC-LR content was detected by HPLC to evaluate the safety of the high voltage electrical discharges method on removing $M$. aeruginosa.

\section{Results and discussion}

The density of the untreated sample of algae $\left(\mathrm{OD}_{680}\right)$ gradually increased from 0.074 to 0.223 over 5 days after high voltage electrical discharges was shown in Fig. 2. At first, during the incubation time, all of the treated groups' OD value was declined compared to the control group. We observed that treated samples turned from green to yellow and some algae settled to the bottom. But the density of all treated samples was reduced to different degrees during 5 days during incubation time. For algae treated for $4 \mathrm{kV}$ and $5 \mathrm{kV}$ groups, the $\mathrm{OD}_{680}$ decreased almost linearly to as low as 0.02 after 5 days culture, amounting to a reduction of $73 \%$. While for the $3 \mathrm{kV}$ groups, the removal rate was $36 \%$ only. The statistical differences between the $3 \mathrm{kV}$ and $4 \mathrm{kV}$ groups, and the $3 \mathrm{kV}$ and $5 \mathrm{kV}$ groups was in significant, but there was no statistical differences between the $4 \mathrm{kV}$ and $5 \mathrm{kV}$ groups. And the final optical density in these cultures after 5 days was no regrowing.

Similarly, the change in chlorophyll- $a$ content resembled that of cell density (which was reasonable, since the concentration of chlorophyll- $a$ was in proportion to cell number). The chlorophyll-a content of untreated algae increased significantly from $0.096 \mathrm{mg} / \mathrm{L}$ to $0.46 \mathrm{mg} / \mathrm{L}$ over the 5 days growth period, while all treated samples showed a rapid decrease trend. However, in contrast to what was observed for cell density, the chlorophyll- $a$ content in samples removal rate was higher than OD 680 , The $3 \mathrm{kV}$, $4 \mathrm{kV}, 5 \mathrm{kV}$ treated group 's removal rate was $51 \%, 78 \%, 90 \%$, respectively after 5 days incubation. The OD value and chlorophyll- $a$ content was showed in Figure. 2 and Figure. 3.

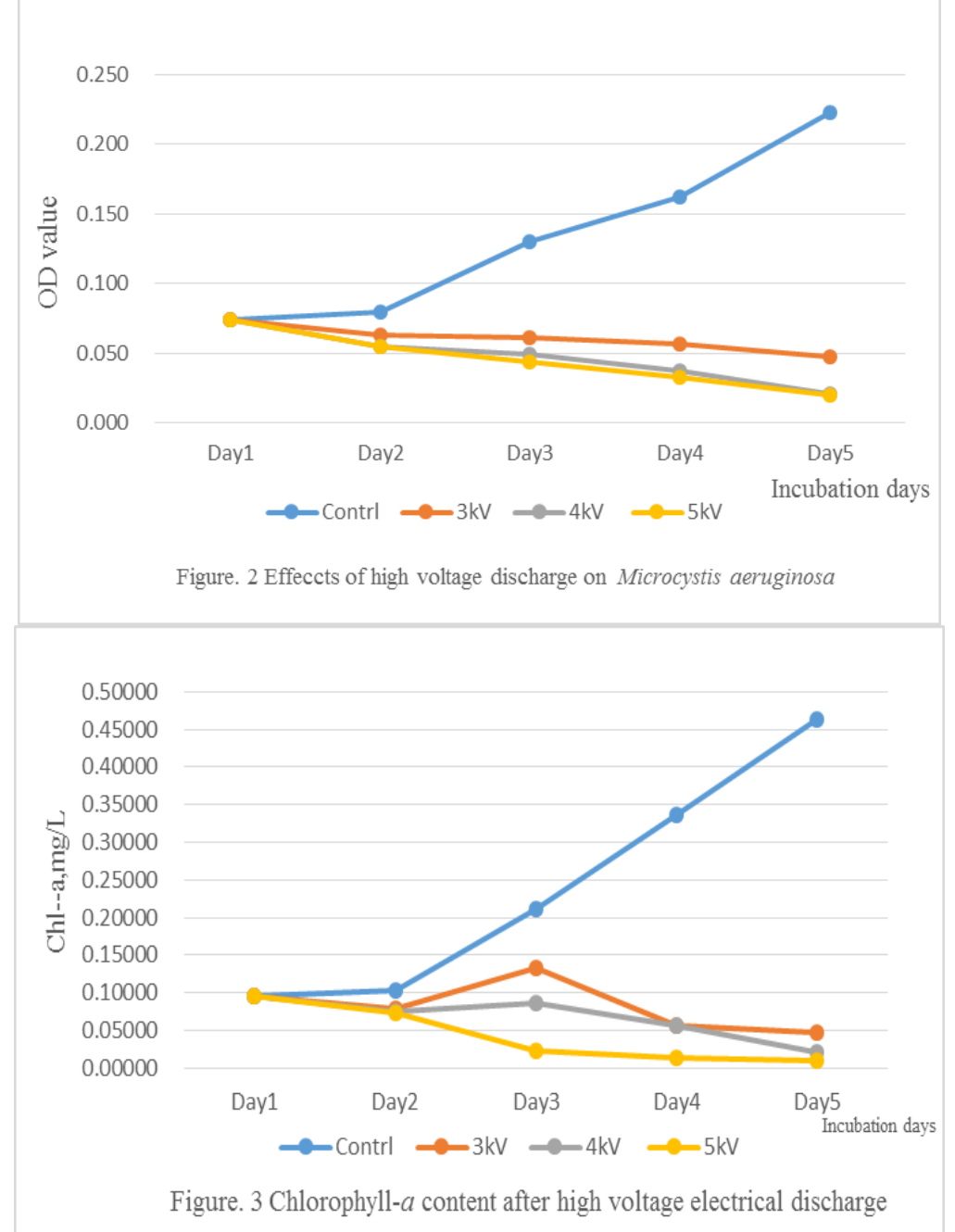

The curves show that the Chl- $a$ content was very similar to the cell density. The damaged cells may cause by physical and chemical actions due to electrical discharge process increased with an increase 
in the treatment time. The application of HVED to biological cells in water causes buildup of electric field at the cell membrane and consequently a change in voltage across the membrane, which induces an additional transmembrane potential. If the additional transmembrane potential reaches and overruns a critical value (normally $1 \mathrm{~V}$ for biological lipid membrane), the membrane permeability increases to such a level that either the cell needs from seconds to hours to recover, or pores are generated in the membrane of sizes which allow the exchange of macromolecules and cell death may occur. Meanwhile, chemically active species, including $\mathrm{OH} \bullet, \mathrm{H} \bullet, \mathrm{O} \bullet, \mathrm{O}_{3}$ and $\mathrm{H}_{2} \mathrm{O}_{2}$, intense UV radiation and over pressure shock waves could attack the cell membrane and wall, disrupt membrane integrity, or electrolyze the molecules in the cell surface, which made pores formed in the cytoplasmic membrane, and the cellular materials released from the cell, including Chl- $a$ and the damaged cells split into many fragments.

HVED can produce a variety of plasma, including free radicals, ozone, hydrogen peroxide, etc. during the discharge progress, but also produce shock waves and strong ultraviolet light, this series of physical and chemical reactions lead algal cell to death, chlorophyll-a release extracellular. In addition, combined with UV light or $\mathrm{H}_{2} \mathrm{O}_{2}$ produced by the discharge system, the removal of algae in the liquid discharge system also reduced the MC-LR concentration in water. According to our experiment results, the algae removal rate was depends on the input voltage, when the voltage is higher, the cell density and Chl- $a$ content is lower. The MC-LR results reveal that the initial concentration of the MC-LR was $0.62 \mu \mathrm{g} / \mathrm{ml}, 5$ days later, the control group' $\mathrm{MC}$-LR was up to $1.0 \mu \mathrm{g} / \mathrm{ml}$. While the $4 \mathrm{kV}$ group and the $5 \mathrm{kV}$ group's MC-LR concentration was decreased to $0.40 \mu \mathrm{g} / \mathrm{ml}$ and $0 \mu \mathrm{g} / \mathrm{ml}$ respectively.
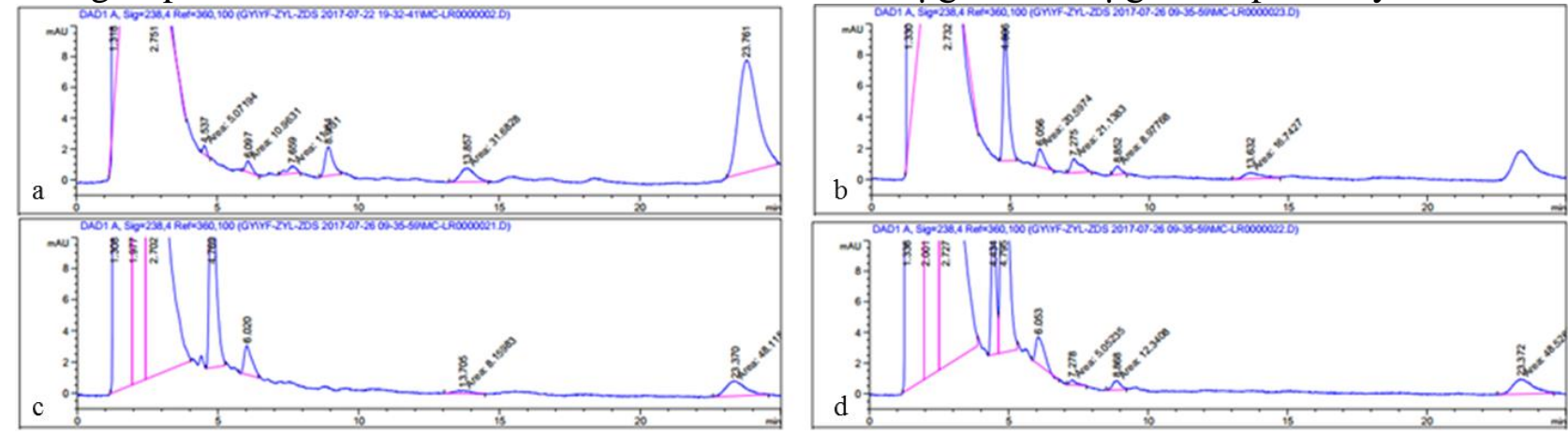

Figure. 4 the initial MC-LR concentration of algae (a) MC-LR concentration of algae of control group (b) MC-LR concentration of $4 \mathrm{kV}$ group HVED treatment after 5 days (c) MC-LR concentration of $5 \mathrm{kV}$ group HVED treatment after 5 days (d)

MC-LR has a large molecular weight of 995 and contains the structures of Adda, D-Glu, Mdha, During the plasma discharge process, high-energy electrons and high oxidative species such as $\cdot \mathrm{OH} / \mathrm{O}_{2}$ and $\mathrm{O}_{3}$ were formed. Base on several literature works and on the molecular structure analysis conducted in our study, a possible degradation mechanism of MC-LR in pulsed discharge system. Hydroxyl radicals are the vital oxidants that dominate the plasma oxidations in water treatment. Their reactions with organic compounds may be differentiated into three different mechanisms: abstraction of hydrogen atom, electrophilic addition to unsaturated bond and electron transfer. In the case of saturated aliphatic hydrocarbons or alcohols, hydrogen abstraction is primary for organic abatement with yielding $\mathrm{H}_{2} \mathrm{O}$ and an organic radical. As for olefins or aromatic hydrocarbons, $\mathrm{C}$-centered radical with a hydroxyl group at the $\alpha-\mathrm{C}$ atom can be formed with $\mathrm{OH}$ radical addition to unsaturated double carbon-carbon bonds of organic compound. Besides, reduction of hydroxyl radicals to hydroxide anions by an organic substrate is of particular interest in the cases where hydrogen abstraction or electrophilic addition reactions may be disfavored by multiple halogen substitution or steric hindrance. 


\section{Summary}

The study shows that high voltage electrical discharges method has the potential to be used as an effective measure for controlling the growth of algae and MC-LR, and $5 \mathrm{kV}$ voltage can not only achieve good algae removal effect, but also can removal MC-LR completely.

\section{References}

[1]. Neil J. M. O., Davis T. W., Burford M. A., et al. The rise of harmful cyanobacteria blooms: The potential roles of eutrophication and climate change. Harmful Algae. 2012. 14: 313-334.

[2]. Xu Hai, Paerl Hans W., Zhu Guangwei, et al. Long-term nutrient trends and harmful cyanobacterial bloom potential in hypertrophic Lake Taihu, China. Hydrobiologia. 2017. 787(1): 229-242.

[3]. Koreiviene J., Anne O., Kasperoviciene J., et al. Cyanotoxin management and human health risk mitigation in recreational waters. Environ Monit Assess. 2014. 186(7): 4443-4459.

[4]. Loftin K. A., Graham J. L., Hilborn E. D., et al. Cyanotoxins in inland lakes of the United States: Occurrence and potential recreational health risks in the EPA National Lakes Assessment 2007. Harmful Algae. 2016. 56: 77-90.

[5]. Backer L. C., Manassaram-Baptiste D., LePrell R., et al. Cyanobacteria and algae blooms: Review of health and environmental data from the Harmful Algal Bloom-Related Illness Surveillance System (HABISS) 2007-2011. Toxins (Basel). 2015. 7(4): 1048-1064.

[6]. Dodds W. K., Bouska W. W., Eitzmann J. L., et al. Eutrophication of U.S. freshwaters: analysis of potential economic damages. Environ Sci Technol. 2009. 43(1): 12-19.

[7]. Yang M., Yu J., Li Z., et al. Taihu Lake not to blame for Wuxi's woes. Science. 2008. 319(5860): 158.

[8]. Schmidt Kathrin Rachel, der Beek Tim Aus, Dai Xiaohu, et al. Since 2015 the SinoGerman research project SIGN supports water quality improvement in the Taihu region, China. Environmental sciences Europe. 2016. 28(1): 24.

[9]. Urrutia-Cordero P., Ekvall M. K., Hansson L. A. Controlling Harmful Cyanobacteria: Taxa-Specific Responses of Cyanobacteria to Grazing by Large-Bodied Daphnia in a Biomanipulation Scenario. PLoS One. 2016. 11(4): e153032.

[10]. Paerl Hans W., Xu Hai, McCarthy Mark J., et al. controlling harmful cyanobacterial blooms in a hyper-eutrophic lake (Lake Taihu, China): The need for a dual nutrient ( $\mathrm{N} \& \mathrm{P}$ ) management strategy. WATER RESEARCH. 2011. 45(5): 1973-1983.

[11]. Codd G. A., Morrison L. F., Metcalf J. S. Cyanobacterial toxins: risk management for health protection. Toxicol Appl Pharmacol. 2005. 203(3): 264-272.

[12]. Serrano Tania, Dupas Remi, Upegui Erika, et al. Geographical modeling of exposure risk to cyanobacteria for epidemiological purposes. ENVIRONMENT INTERNATIONAL. 2015. 81: $18-25$.

[13]. Wang Cui-Hua, Li Guo-Feng, Wu Yan, et al. Role of Bipolar Pulsed DBD on the Growth of Microcystis aeruginosa in Three-Phase Discharge Plasma Reactor. Plasma Chemistry and Plasma Processing. 2007. 27(1): 65-83.

[14]. Boussetta N., Vorobiev E., Le L. H., et al. Application of electrical treatments in alcoholic solvent for polyphenols extraction from grape seeds. LWT - Food Science and Technology. 2012. 46(1): 127-134.

[15]. Jiang Bo, Zheng Jingtang, Qiu Shi, et al. Review on electrical discharge plasma technology for wastewater remediation. CHEMICAL ENGINEERING JOURNAL. 2014. 236: 348-368. 